\title{
Direct Preparation of Nano-Quasicrystals via a Water-Cooled Wedge-Shaped Copper Mould
}

\author{
Zhifeng Wang, Weimin Zhao, Chunling Qin, Yan Cui, Shenglei Fan, and Junqing Jia
}

School of Materials Science and Engineering, Hebei University of Technology, Tianjin 300130, China

Correspondence should be addressed to Weimin Zhao,wmzhao@yahoo.com

Received 30 June 2011; Accepted 9 August 2011

Academic Editor: Bo Zou

Copyright $\odot 2012$ Zhifeng Wang et al. This is an open access article distributed under the Creative Commons Attribution License, which permits unrestricted use, distribution, and reproduction in any medium, provided the original work is properly cited.

We have successfully synthesized multicomponent Mg-based nano-quasicrystals (nano-QCs) through a simple route by using a water-cooled wedge-shaped copper mould. Nanoscale QCs are prepared directly on tip of wedge-shaped castings. The further study shows that nano-QCs in the $\mathrm{Mg}_{71} \mathrm{Zn}_{26} \mathrm{Y}_{2} \mathrm{Cu}_{1}$ alloy show well microhardness of greater than HV450. Electrochemical properties of three kinds of quasicrystal alloys are investigated in simulated seawater. The $\mathrm{Mg}_{71} \mathrm{Zn}_{26} \mathrm{Y}_{2} \mathrm{Cu}_{1}$ nano-QC alloy presents the best corrosion resistance in this study for the formation of well-distributed nano-QC phases $(1 \sim 5 \mathrm{~nm})$ and polygonal $\mathrm{Mg}_{2}(\mathrm{Cu}, \mathrm{Y})$ nanophases $(40 \sim 50 \mathrm{~nm})$.

\section{Introduction}

Quasicrystals (QCs) are aperiodic solids whose atomic arrangements have symmetries (typically five- or tenfold) that are forbidden for conventional crystallography [1] and have long been thought forbidden in nature. It brings about a paradigm shift in solid-state physics when the first QC example is obtained in a rapidly solidified Al-Mn alloy [2]. The unexpected discovery of QCs presents scientists with a new, puzzling class of materials and involves hundreds of researchers in this realm. In the past nearly thirty years, QCs in various systems have been synthesized in laboratories $[3,4]$ and have also been discovered in natural minerals [5]. These QCs possess a host of unusual mechanical and physical properties [6]. Though they cannot be applied directly as structural materials for their innate brittleness, they present high microhardness which makes them used as good strengthening phases for some flexible matrix. Accordingly, diverse QC master alloys have been successfully synthesized and added into different commercial alloys [7, 8].

Usually, nano-quasicrystals (nano-QCs) can be synthesized through two kinds of ways. Nano-QCs are known to form in annealed $[9,10]$ or ball-milled [11] metallic glasses. Moreover, they can also be fabricated in extruded $[12,13]$, rolled [14], or wrought [15] Mg-based alloys at high temperature. These nano-QC alloys exhibit better mechanical properties compared with their corresponding glasses or conventional crystalline alloys [16]. So, the nanoQC alloy is a kind of very promising material. In this study, we have synthesized nano-QC alloys through a new and simple route instead of traditional heat treatment and texturing process. Thus, the forming process of nano-QC alloy can strongly be simplified. At the same time, the costing of manufacture equipment can highly be cut down.

On the other hand, magnesium alloys present poor corrosion resistance. They can easily be eroded either in acid, neutral, or alkali solutions, even in pure water [17]. So, their further applications are restrained. Considering the excellent corrosion resistance of QCs [18], we manage to in situ synthesis Mg-based nano-QCs in Mg-Zn-Y alloys which are hopeful to show their improved corrosion resistance.

In past work, we have synthesized quarternary spherical Mg-Zn-Y-based QC phase [19] by controlling compositions and undercooling conditions of the melts. In order to fabricate nanoscale QCs, we improve the cooling condition in this paper by using a water-cooled wedge-shaped copper mould [20]. Multicomponent spherical nano-QCs are successfully synthesized and their electrochemical properties are investigated in simulated seawater. 
TABLE 1: Nominal composition of the experimental alloys.

\begin{tabular}{lccccc}
\hline \multirow{2}{*}{ Alloy No. } & \multicolumn{5}{c}{ Alloy compositions (at. \%) } \\
& $\mathrm{Mg}$ & $\mathrm{Zn}$ & $\mathrm{Y}$ & $\mathrm{Cu}$ & $\mathrm{Ni}$ \\
\hline $1 \#$ & 72.0 & 26.0 & 2.0 & - & - \\
$2 \#$ & 71.0 & 26.0 & 2.0 & 1.0 & - \\
$3 \#$ & 71.0 & 26.0 & 2.0 & 0.5 & 0.5 \\
\hline
\end{tabular}

\section{Experimental}

The experimental alloys (Table 1) were produced by a reformed crucible electric resistance furnace $\left(\mathrm{SG}_{2}-5-10 \mathrm{~A}\right.$, China), melted under the mixture of $\mathrm{CO}_{2} / 0.5 \mathrm{vol} . \% \mathrm{SF}_{6}$ protective atmosphere, using $\mathrm{Mg}(99.95 \%)$ and $\mathrm{Zn}(99.90 \%)$ ingots, $\mathrm{Ni}(99.99 \%)$ and $\mathrm{Cu}(99.99 \%)$ powder, and $\mathrm{Mg}$ $29.05 \%$ Y master alloy. Stirring for $2 \mathrm{~min}$ by impellor at $1073 \mathrm{~K}$ and holding for $5 \mathrm{~min}$ above $1053 \mathrm{~K}$, the melt was poured and cooled in a water-cooled wedge-shaped copper mould. Samples were taken on tip of castings as shown in Figure 1.

The morphology observation of QCs was conducted using transmission electron microscopy (TEM, DEOL JEM-2010FEF, Japan). Microhardness of QC alloys was examined by microhardness tester (HXD-1000, China). The electrochemical properties of specimens were tested in simulated seawater $\left(2.73 \% \mathrm{NaCl}, 0.24 \% \mathrm{MgCl}_{2}, 0.34 \%\right.$ $\mathrm{MgSO}_{4}, 0.11 \% \mathrm{CaCl}_{2}, 0.08 \% \mathrm{KCl}$, and $96.5 \%$ deionized water, vol.\%) by an electrochemical workstation (Gamry, PCI4-750, USA) with a sweep rate of $10 \mathrm{mV} / \mathrm{s}$. A saturated calomel electrode (SCE) was used for the reference electrode.

\section{Results and Discussion}

TEM photos of QC alloys in different sample positions are shown in Figure 2. Three kinds of componential micro/nano-QC phases are synthesized on tip of wedge-shaped castings. Energy-dispersive spectroscopy (EDS) analysis (Figure 3 ) shows that micro-/nano-QC phases in Position B of Alloy $1 \sim$ Alloy 3 are Mg-Zn-Y phase, Mg-Zn-Y-Cu phase, and $\mathrm{Mg}-\mathrm{Zn}-\mathrm{Y}-\mathrm{Cu}-\mathrm{Ni}$ phase, respectively. The selected area electron-diffraction (SAED) patterns with typical fivefold rotational symmetry identify that these micro-/nano-QC phases are icosahedral QCs. Among all QCs, QCs in Position A of Alloy 1 show petal-like morphology, while others show spherical morphology. From the further analysis in Table 2, we can see that in alloys with same components, QCs in Position B are smaller than those in Position A, while QC microhardness in Position B is greater than that in Position A. After introducing $\mathrm{Cu}(-\mathrm{Ni})$ into $\mathrm{Mg}-\mathrm{Zn}-\mathrm{Y}$ alloys, we can see in the same sample position, QC size of Alloy 2 and Alloy 3 is obviously smaller than that of Alloy 1. QC size of Alloy 2 in Position A is close to that of Alloy 1 in Position B. NanoQC spheres about 8 30 $\mathrm{nm}$ and $1 \sim 5 \mathrm{~nm}$ are synthesized in Position B of Alloy 3 and Alloy 2, respectively. It shows from the microhardness testing that the smaller the QC spheres, the greater their value of microhardness. Furthermore, the microhardness of nano-QC spheres in Position B of Alloy 2 exceeds HV450, which shows fascinating properties.

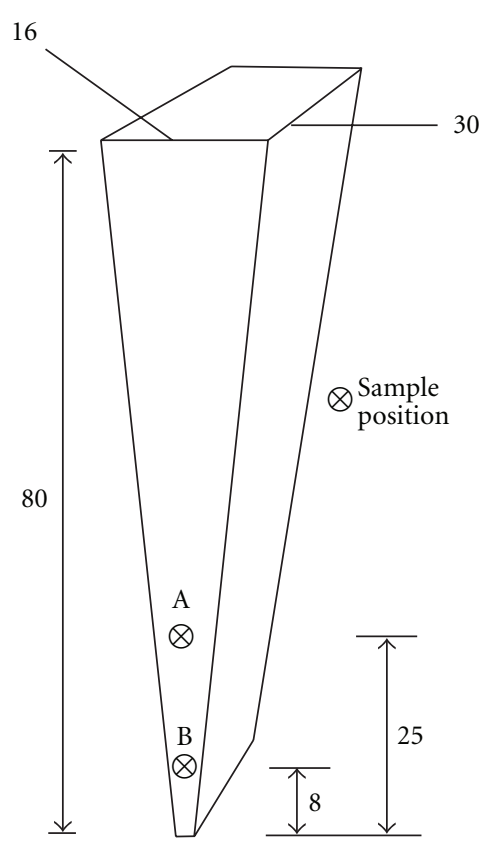

FIGURE 1: Sketch map of a wedge-shaped casting (mm).

Figure 4 shows the potentiodynamic polarization curves of QC alloys (Position B) measured in simulated seawater open to air at room temperature. We can see that $\mathrm{Mg}_{71} \mathrm{Zn}_{26} \mathrm{Y}_{2} \mathrm{Cu}_{1}$ nano-QC alloy presents high corrosion resistance in simulated seawater and its corrosion resistance is much better than that of $\mathrm{Mg}_{72} \mathrm{Zn}_{26} \mathrm{Y}_{2}$ and $\mathrm{Mg}_{71} \mathrm{Zn}_{26} \mathrm{Y}_{2} \mathrm{Cu}_{0.5} \mathrm{Ni}_{0.5} \mathrm{QC}$ alloys. The further study shows that this result can be ascribed to the existence of welldistributed nano-QC phases (shown in Figure 5 by red arrows) and polygonal $\mathrm{Mg}_{2}(\mathrm{Cu}, \mathrm{Y})$ phases [21]. These highcorrosion resistance phases decrease the anodic passive current density, improve the polarization resistance, cut down the corrosion rate (Table 3 ), and finally improve the corrosion resistance of the $\mathrm{Mg}-\mathrm{Zn}$-Y-based alloy markedly. $\mathrm{Cu}$ and $\mathrm{Ni}$ have long been considered as harmful elements for improving corrosion resistance of Mg-based alloy [22], however they are used to synthesize nano-QC spheres in this paper. Due to high-corrosion resistance of QC phases, $\mathrm{Mg}_{71} \mathrm{Zn}_{26} \mathrm{Y}_{2} \mathrm{Cu}_{1}$ and $\mathrm{Mg}_{71} \mathrm{Zn}_{26} \mathrm{Y}_{2} \mathrm{Cu}_{0.5} \mathrm{Ni}_{0.5}$ nano-QC alloys present better corrosion resistance than $\mathrm{Mg}_{72} \mathrm{Zn}_{26} \mathrm{Y}_{2} \mathrm{QC}$ alloy. Moreover, the corrosion resistance of $\mathrm{Mg}_{71} \mathrm{Zn}_{26} \mathrm{Y}_{2} \mathrm{Cu}_{1}$ nano-QC alloys is higher than $\mathrm{Mg}_{71} \mathrm{Zn}_{26} \mathrm{Y}_{2} \mathrm{Cu}_{0.5} \mathrm{Ni}_{0.5}$ nanoQC alloys for the higher damage level of $\mathrm{Ni}$ to the corrosion resistance of magnesium alloy than that of $\mathrm{Cu}$ when they have same contents [22].

It was reported that a large negative enthalpy of mixing and/or existence of Frank-Kasper-type phases appear to be the crucial criteria for the formation of nano-quasicrystalline phase in any system [23]. Meanwhile, Mg-Zn-Y-based QCs just belong to Frank-Kasper-type phases [24] and have a certain negative enthalpy of mixing. So theoretically, Mg$\mathrm{Zn}$-Y-based nano-QCs can be formed in a proper cooling conditions. The past cooling rate the researchers made to produce QCs was whether too high or too low, and 

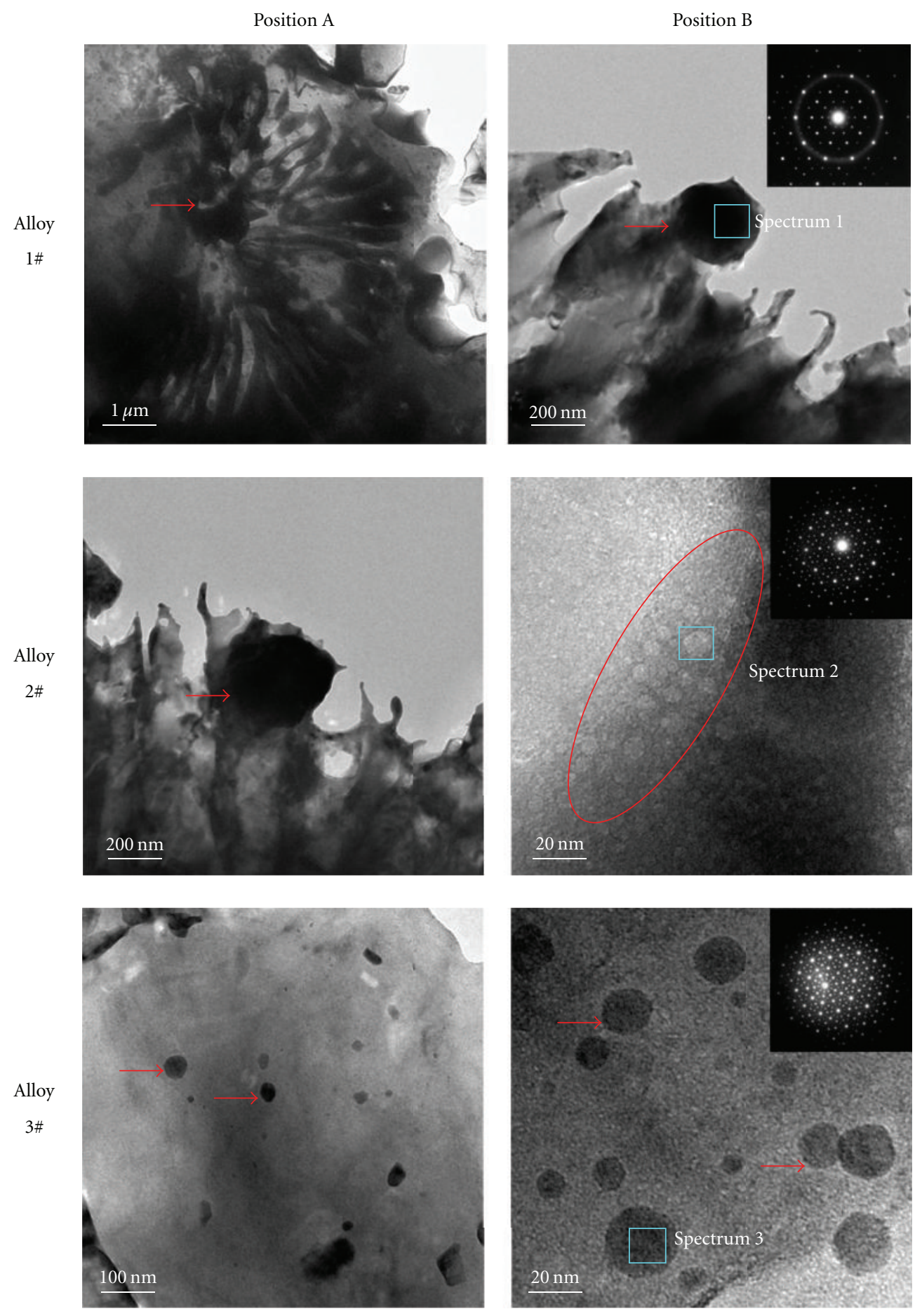

FIGURE 2: TEM photos of micro/nano-QC alloys and QC typical selected area electron-diffraction (SAED) patterns on Position B of different alloys.

was not content with the forming conditions of nanoQCs. This route just meets the demands for forming nanoscale QCs. So, nano-QCs are successfully produced in this paper. Moreover, the additions of $\mathrm{Cu}$ and Ni improve the degree of constitutional supercooling of $\mathrm{Mg}-\mathrm{Zn}-\mathrm{Y}$ melts and reduce the crucial criteria radius for forming spherical QCs. However, increasing thermodynamics undercooling coming from water-cooled wedge-shaped copper mould makes it still possible to form spherical QCs. At the same time, the alloy components designed for this study is based on the three empirical rules [25] for the formation of metallic glass. It has been widely accepted that quasicrystals and at least some metallic glasses are built up with icosahedral clusters [26]. The short-range atomic configuration is very similar 


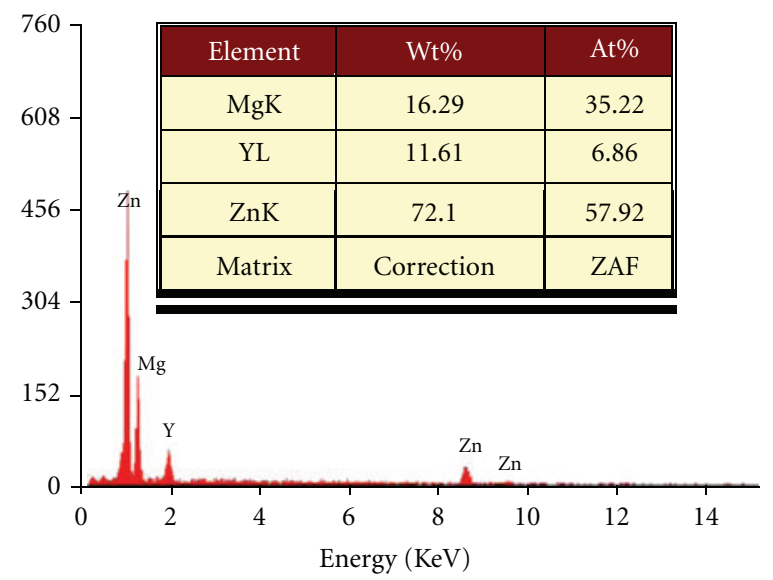

(a)

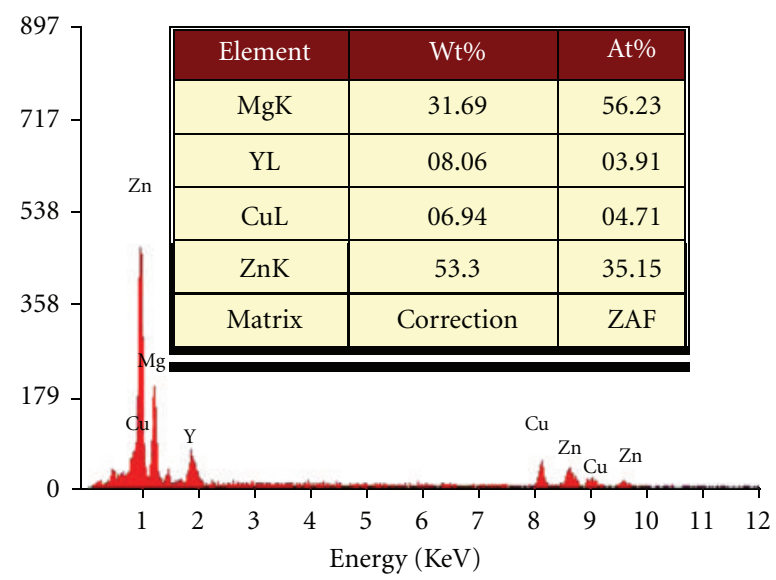

(b)

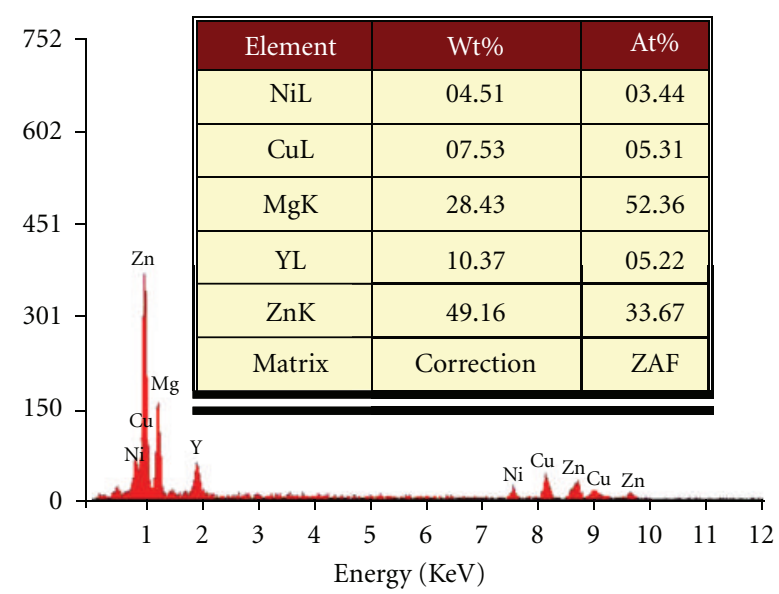

(c)

Figure 3: Energy-dispersive spectroscopy (EDS) analysis of QCs in Position B.

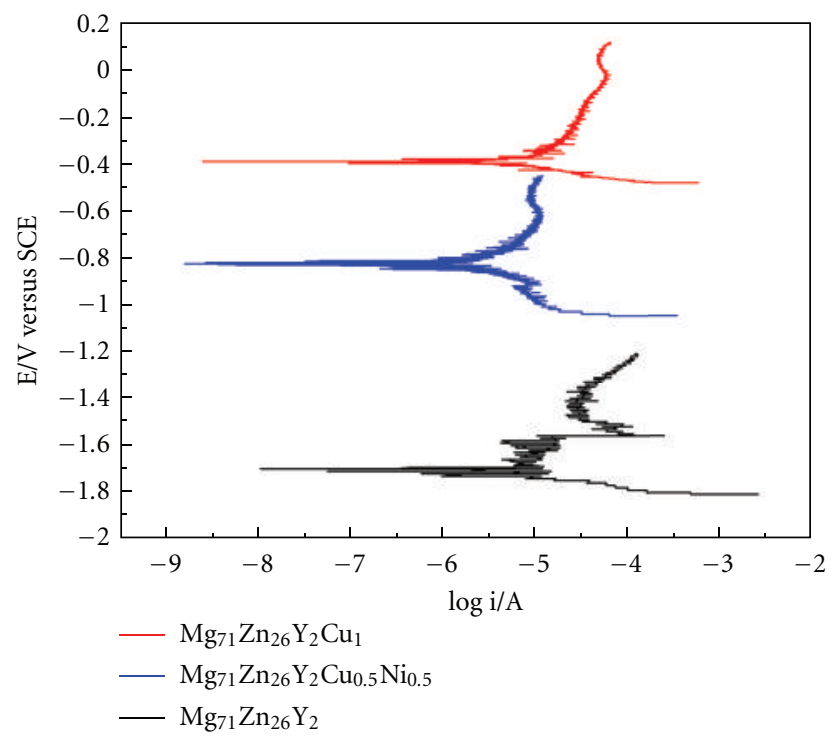

FIGURE 4: Potentiodynamic polarization curves of QC alloys (Position B) measured in simulated seawater open to air at room temperature. 


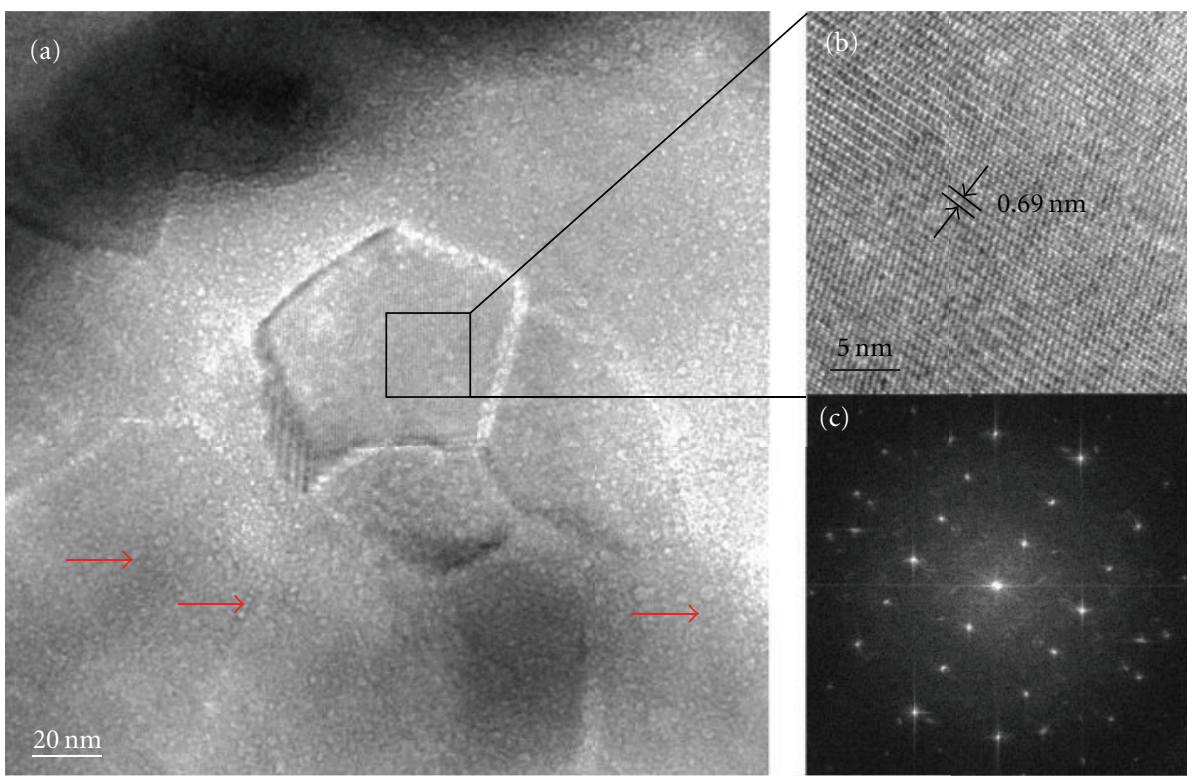

FIGURE 5: Pentagonal nanophase in Alloy 2 (a) TEM photo. (b) Magnifying TEM photo and (c) its fast Fourier transform (FFT) pattern.

TABLE 2: Comparisons of the quasicrystals (QCs).

\begin{tabular}{ccccc}
\hline Alloy & Sample position & QC size (diameter)/nm & QC morphology & Microhardness /HV \\
\hline 1 & A & $650-900$ & Petal-like & 324 \\
& B & $330-340$ & Spherical & 375 \\
\hline 2 & A & $370-400$ & Spherical & 367 \\
& B & $1.0-5.0$ & Spherical & 459 \\
\hline & A & $20-55$ & Spherical & 412 \\
& B & $8-30$ & Spherical & 438 \\
\hline
\end{tabular}

TABLE 3: Corrosion parameters obtained from potentiodynamic polarization curves for Position B of QC alloys in simulated seawater.

\begin{tabular}{lccc}
\hline Specimen & $I_{\text {corr }} / \mu \mathrm{A} / \mathrm{cm}^{-2}$ & $R_{p} / \mathrm{k} \Omega$ & Corrosion Rate $/ \mathrm{mpy}$ \\
\hline 1 & 11.09 & 6.925 & 19.298 \\
2 & 2.035 & 14.76 & 1.522 \\
3 & 3.762 & 8.105 & 3.084 \\
\hline
\end{tabular}

$I_{\text {corr }}$ : corrosion current; $R_{p}$ : polarization resistance.

between the quasicrystal and amorphous phases [27]. On the tip of the wedge-shaped ingots, its cooling conditions is just suitable for these icosahedral clusters to be nucleation of QCs. And then, it leaves very short time for quasicrystal growth. So, it is nano-QCs that form in this route instead of metallic glasses.

\section{Conclusions}

After introducing $\mathrm{Cu}(-\mathrm{Ni})$ into $\mathrm{Mg}-\mathrm{Zn}-\mathrm{Y}$ alloys, spherical nano-quasicrystals (nano-QCs) are directly prepared on tip of wedged-shaped castings. Nano-QCs in the $\mathrm{Mg}_{71} \mathrm{Zn}_{26} \mathrm{Y}_{2} \mathrm{Cu}_{1}$ alloy show well microhardness of greater than HV450. At the same time, the $\mathrm{Mg}_{71} \mathrm{Zn}_{26} \mathrm{Y}_{2} \mathrm{Cu}_{1}$ nanoQC alloy presents high corrosion resistance in simulated seawater for the formation of well-distributed nano-QC phases $(1 \sim 5 \mathrm{~nm})$ and polygonal $\mathrm{Mg}_{2}(\mathrm{Cu}, \mathrm{Y})$ nanophases $(40 \sim 50 \mathrm{~nm})$.

\section{Acknowledgments}

The authors would like to thank the financial supports from both Natural Science Foundation of Hebei Province, China (no. E2010000057) and International Science \& Technology Cooperation Program of China (no. 2010DFA51850). The technical assistance of TEM testing from Dr. H. T. Fan, China National Academy of Nanotechnology \& Engineering is also acknowledged.

\section{References}

[1] P. Thiel, "Quasicrystals: when all pieces fit together," Nature Materials, vol. 6, no. 1, pp. 11-12, 2007.

[2] D. Shechtman, I. Blech, D. Gratias, and J. W. Cahn, "Metallic phase with long-range orientational order and no translational symmetry," Physical Review Letters, vol. 53, no. 20, pp. 19511953, 1984. 
[3] Z. Luo, S. Zhang, Y. Tang, and D. Zhao, "Quasicrystals in ascast Mg-Zn-RE alloys," Scripta Metallurgica et Materiala, vol. 28, no. 12, pp. 1513-1518, 1993.

[4] A. P. Tsai, A. Inoue, and T. Masumoto, "A stable quasicrystal in Al-Cu-Fe system," Japanese Journal of Applied Physics, vol. 26, no. 9, pp. L1505-L1507, 1987.

[5] L. Bindi, P. J. Steinhardt, N. Yao, and P. J. Lu, "Natural quasicrystals," Science, vol. 324, no. 5932, pp. 1306-1309, 2009.

[6] A. V. Blaaderen, "Quasicrystals from nanocrystals," Nature, vol. 461, no. 7266, pp. 892-893, 2009.

[7] J. Zhang, L. Pei, H. Du, W. Liang, C. Xu, and B. Lu, "Effect of Mg-based spherical quasicrystals on microstructure and mechanical properties of AZ91 alloys," Journal of Alloys and Compounds, vol. 453, no. 1-2, pp. 309-315, 2008.

[8] Z. Wang, W. Zhao, H. Li, and C. Liang, "Fabrication of quaternary $\mathrm{Mg}-\mathrm{Zn}$-Y-Ce quasi-crystal alloys and their strengthening effects on AZ91 magnesium alloys," China Foundry, vol. 7, no. 4, pp. 342-348, 2010.

[9] J. Saida, M. Matsushita, and A. Inoue, "Nano icosahedral quasicrystals in Zr-based glassy alloys," Intermetallics, vol. 10, no. 11-12, pp. 1089-1098, 2002.

[10] M. Galano, F. Audebert, I. C. Stone, and B. Cantor, "Nanoquasicrystalline Al-Fe-Cr-based alloys. Part I: phase transformations," Acta Materialia, vol. 57, no. 17, pp. 5107-5119, 2009.

[11] S. Scudino, U. Kühn, L. Schultz, H. Breitzke, K. Lüders, and J. Eckert, "Formation of quasicrystals in ball-milled amorphous Zr-Ti-Nb-Cu-Ni-Al alloys with different Nb content," Journal of Materials Science, vol. 39, no. 16-17, pp. 5483-5486, 2004.

[12] Y. Liu, G. Yuan, C. Lu, W. Ding, and J. Jiang, "The role of nanoquasicrystals on the ductility enhancement of asextruded Mg-Zn-Gd alloy at elevated temperature," Journal of Materials Science, vol. 43, no. 16, pp. 5527-5533, 2008.

[13] A. Singh, M. Watanabe, A. Kato, and A. P. Tsai, "Microstructure and strength of quasicrystal containing extruded MgZn-Y alloys for elevated temperature application," Materials Science and Engineering A, vol. 385, no. 1-2, pp. 382-396, 2004.

[14] A. Müller, G. Garcés, P. Pérez, and P. Adeva, "Grain refinement of Mg-Zn-Y alloy reinforced by an icosahedral quasicrystalline phase by severe hot rolling," Journal of Alloys and Compounds, vol. 443, no. 1-2, pp. L1-L5, 2007.

[15] D. H. Kim, J. Y. Lee, H. K. Lim, W. T. Kim, and D. H. Kim, "Effect of $\mathrm{Al}$ addition on the elevated temperature deformation behavior of Mg-Zn-Y alloy," Materials Science and Engineering A, vol. 487, no. 1-2, pp. 481-487, 2008.

[16] A. Inoue and A. Takeuchi, "Recent progress in bulk glassy, nanoquasicrystalline and nanocrystalline alloys," Materials Science and Engineering A, vol. 375-377, no. 1-2, pp. 16-30, 2004.

[17] F. Shi, Y. C. Yu, X. F. Guo, Z. M. Zhang, and Y. Y. Li, "Corrosion behavior of as-cast $\mathrm{Mg}_{68} \mathrm{Zn}_{28} \mathrm{Y}_{4}$ alloy with Iphase," Transactions of Nonferrous Metals Society of China, vol. 19, no. 5, pp. 1093-1097, 2009.

[18] V. N. Balbyshev, D. J. King, A. N. Khramov, L. S. Kasten, and M. S. Donley, "Investigation of quaternary Al-based quasicrystal thin films for corrosion protection," Thin Solid Films, vol. 447-448, pp. 558-563, 2004.

[19] Z. Wang, W. Zhao, H. Li, J. Ding, Y. Li, and C. Liang, "Effect of titanium, antimony, cerium and carbon nanotubes on the morphology and microhardness of Mg-based icosahedral quasicrystal phase," Journal of Materials Science \& Technology, vol. 26, no. 1, pp. 27-32, 2010.

[20] M. A. Suarez, O. Alvarez, M. A. Alvarez, R. A. Rodriguez, S. Valdez, and J. A. Juarez, "Characterization of microstructures obtained in wedge shaped Al-Zn-Mg ingots," Journal of Alloys and Compounds, vol. 492, no. 1-2, pp. 373-377, 2010.

[21] J. Zhang, K. Qiu, A. Wang, H. Zhang, M. Quan, and Z. Hu, "Effects of pressure on the solidification microstructure of $\mathrm{Mg}_{65} \mathrm{Cu}_{25} \mathrm{Y}_{10}$ alloy," Journal of Materials Science \& Technology, vol. 20, no. 1, pp. 106-108, 2004.

[22] G. L. Song, Corrosion and Protection of Magnesium Alloys, Chemistry Industry Press, Beijing, China, 2006.

[23] B. S. Murty and K. Hono, "On the criteria for the formation of nanoquasicrystalline phase," Applied Physics Letters, vol. 84, no. 10, pp. 1674-1676, 2004.

[24] R. Sterzel, E. Dahlmann, A. Langsdorf, and W. Assmus, "Preparation of Zn-Mg-rare earth quasicrystals and related crystalline phases," Materials Science and Engineering A, vol. 294-296, pp. 124-126, 2000.

[25] A. Inoue, "Stabilization of metallic supercooled liquid and bulk amorphous alloys," Acta Materialia, vol. 48, no. 1, pp. 279-306, 2000.

[26] C. Dong, W. Chen, Y. Wang et al., "Formation of quasicrystals and metallic glasses in relation to icosahedral clusters," Journal of Non-Crystalline Solids, vol. 353, no. 32-40, pp. 3405-3411, 2007.

[27] A. Inoue, A. P. Tsai, H. M. Kimura, and T. Masumoto, "Enthalpy relaxation behaviour of Al-Si-Cr quasicrystalline and amorphous alloys upon annealing," Journal of Materials Science, vol. 23, no. 2, pp. 429-437, 1988. 

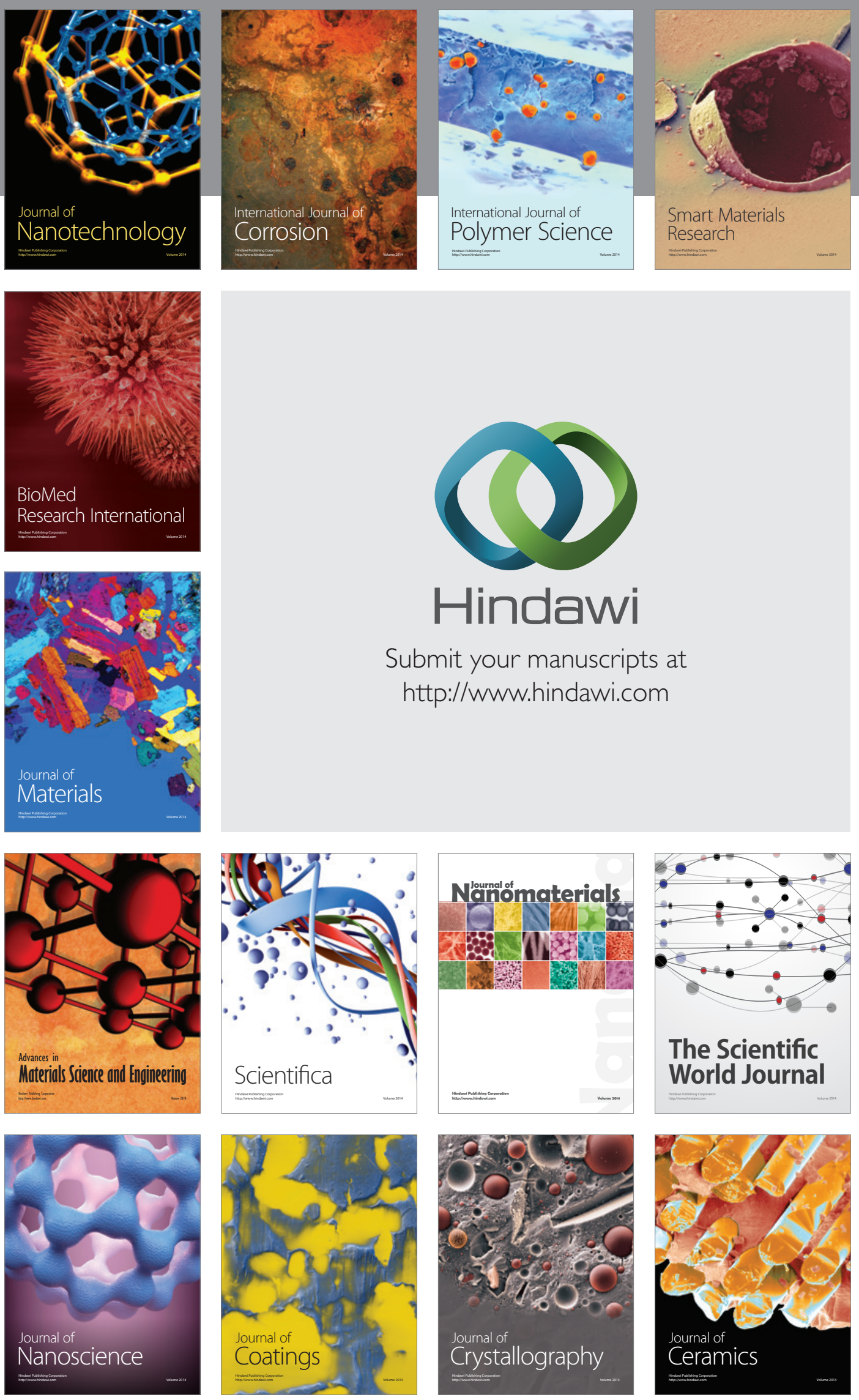

The Scientific World Journal

Submit your manuscripts at

http://www.hindawi.com

\section{World Journal}

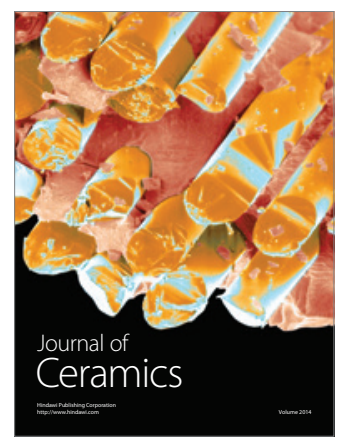

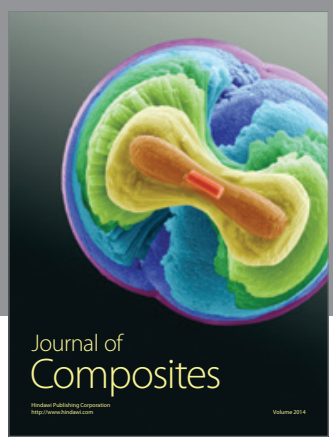
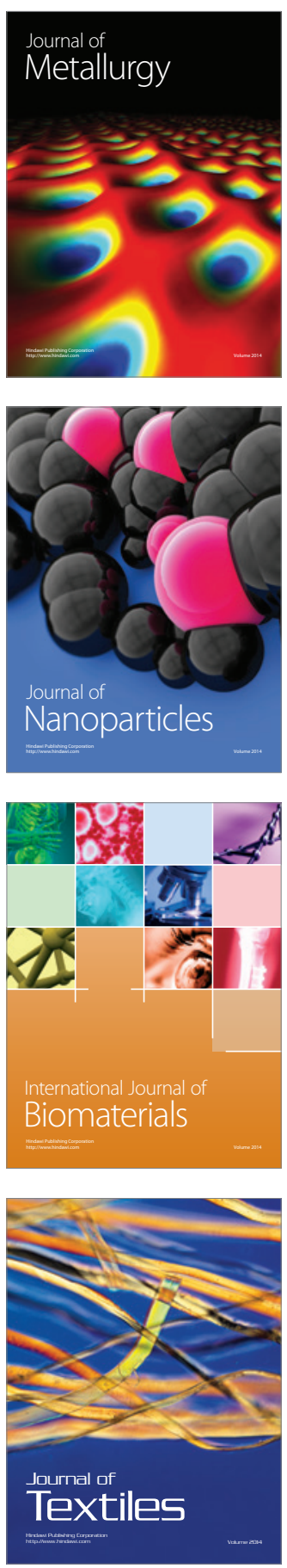